\title{
FORMULASI HAND AND BODY LOTION ANTIOKSKIDAN EKSTRAK DAUN MUDA JAMBU METE
}

\author{
(Anacardium ocidentale L.)
}

\author{
Nirwati Rusli*, Francisca Pandean \\ Akademi Farmasi Bina Husada Kendari \\ Email : nirwatirusli@gmail.com
}

\begin{abstract}
ABSTRAK
Tanaman daun Jambu mete adalah salah satu tanaman yang mengandung senyawa flavonoid yang dapat berperan sebagai antioksidan yaitu mampu menangkap radikal bebas pada kulit. Hand and Body lotion adalah suatu sediaan yang dibuat dari bahan dasar dengan penambahan ekstrak daun jambu mete, serta penambahan bahan lain yang diizinkan dan digunakan untuk kulit. Jenis penelitian yang digunakan adalah eksperimen. Sediaan hand and body lotion dengan 3 konsentrasi yaitu konsentrasi $2 \%$, konsentrasi 3\%, dan konsentrasi 5\% dan dilakukan pengujian evaluasi fisik yaitu uji organoleptik, $\mathrm{pH}$, tipe emulsi, stabilitas emulsi, homogenitas, viskositas dan iritasi. Hasil penelitian menunjukkan bahwa ekstrak daun jambu mete dapat diformulasi dalam kosmetik hand and body lotion. Hasil penelitian menunjukan uji organoleptik diperoleh sediaan semi padat yang berwarna coklat muda dan memiliki aroma khas green tea yang dapat tercampur dengan air dengan tipe emulsi minyak dalam air (M/A), dan stabil yaitu tidak terpisahkan antara fase air dan fase minyak selama penyimpanan.
\end{abstract}

Kata Kunci : Hand and Body Lotion, daun Jambu Mete, antioksidan.

\section{ABSTRACT}

Flavonoid is compound that contain from jambu mete leaves have a role as the antioxidant like a foid from free radikal skin. Hand and body lotion is a preparations that mad from basic lotion material with add pollen jambu mete leaves and other metrial which necessary and use for skin. This research that made in a pollen is eksperiment. Hand and body lotion with three concentration $2 \%$, concentration 3\%, concentration $5 \%$ and do a physical evaluation test are organoleptic, $\mathrm{pH}$, type of emulsion stability, homogeneity, viscosity, and irritation. The result show that a pollen from Jambu Mete leaves can be formulated in cosmetic hand and body lotion. This resultshow that organoleptik test got semi oreparation which is colored light brown and have aroma typical green tea that can mixed with water emulcion type oil in water $(0 / W)$ and stable is not separate between water phase and oil phase until storage.

Keywords : hand and body lotion Jambu Mete leaves, antioxidant. 


\section{PENDAHULUAN}

Tanaman jambu mete merupakan tanaman yang banyak manfaatnya mulai dari akar, batang, daun, dan buahnya (Hakimah, 2012). Daun jambu mete kaya akan antioksidan kandungan mineral yang terdapat dalam daun mete juga sangat berguna sebagai co-faktor serta antioksidan yang sangat ampuh dalam tubuh (Winarsi, 2007).

\section{Seiring}

dengan

berkembangnya ilmu pengetahuan dan peradaban manusia maka bertambah pula kebutuhan manusia dalam berbagai bidang khususnya kosmetik. Kosmetik dibutuhkan untuk berbagai keperluan tubuh yaitu sebagai pembersih tubuh, pengharum tubuh, atau memperindah penampilan (Badan POM, 2004).

Hand and body Lotion adalah sediaan kosmetik pelembab kulit yang termasuk dalam golongan emolien (pelembut) dan memiliki beberapa sifat yaitu sebagai sumber lembab bagi kulit, membuat tangan dan badan menjadi lembut, tetapi tidak berminyak dan mudah dioleskan pada kulit (Wasitaatmadja,1997).
Meningkatnya keinginan masyarakat untuk menggunakan bahan alam ditanggapi dengan banyaknya produk topikal berbahan aktif tanaman untuk perawatan kesehatan, kosmetik dan pencegahan penyakit. Sangat banyak tanaman dapat digunakan sebagai bahan obat untuk menjaga kesehatan sekaligus sebagai bahan kosmetik untuk merawat kecantikan (Anief, 1997).

\section{METODOLOGI}

\section{Jenis Penelitian}

Jenis penelitian yang digunakan adalah penelitian eksperimental, dan penelitian dilakukan dilaboratorium Farmasetika Akademi Farmasi Bina Husada Kendari pada bulan Mei-Juni 2016.

\section{Alat dan Bahan}

Alat yang digunakan ialah batang pengaduk, gelas kimia, gelas ukur, hot plate, rotavapor, $\mathrm{pH}$ meter, sendok tanduk, bejana maserasi, thermometer. Bahan yang digunakan asam stearat, ekstrak daun muda jambu mete, etanol 96\%, gliserin, metil paraben, propil paraben, setil alkohol, tween 80 . 


\section{Pembuatan Ekstrak}

\section{Daun Muda Jambu Mete}

Ditimbang simplisia 500 gram kemudian dimasukkan ke dalam wadah maserasi, lalu direndam dengan pelarut etanol $96 \%$ kemudian diekstraksi secara remaserasi berulang, lalu diuapkan dengan menggunakan rotavapor agar diperoleh ekstrak kental.

\section{Pembuatan Pembuatan Lotion}

\section{Daun Muda Jambu Mete}

Disiapkan alat dan bahan yang akan digunakan, ditimbang semua bahan sesuai dengan perhitungan. Asam stearat, propil paraben, dan setil alkohol yang merupakan fase minyak dicampurkan dan kemudian dipanaskan dalam cawan porselin hingga mencapai suhu $70^{\circ} \mathrm{C}$ sambil di lakukan pengadukan secara konstan ( campuran 1 ). Gliserin dan air yang merupakan fase air di campurkan dan di panaskan hingga suhu $70^{\circ} \mathrm{C}$ dalam wadah yang berbeda di tambahkan metil paraben dan tween 80 secara perlahan ( campuran 2 ). Campuran 1 dan 2 yang merupakan fase minyak dan air di campur sambil terus di aduk sampai suhunya $50^{\circ} \mathrm{C}$ sehingga menjadi lotion. Campuran di tambahkan ekstrak daun muda jambu mete setelah homogen, ditambahkan pewangi green tea secukupnya, sediaan dimasukkan kedalam wadah dan diberikan label kemasan.

\section{HASIL DAN PEMBAHASAN}

\section{a. Pengujian Organoleptik}

Tabel 1. Hasil uji organoleptik Hand and body lotion daun muda Jambu Mete

\begin{tabular}{|c|c|c|c|c|c|}
\hline \multirow[t]{2}{*}{ Pengamatan } & \multirow[t]{2}{*}{ Formula } & \multicolumn{4}{|c|}{ Minggu } \\
\hline & & I & II & III & IV \\
\hline \multirow[t]{3}{*}{ Warna } & A & $\begin{array}{l}\text { Cokelat } \\
\text { muda }\end{array}$ & $\begin{array}{l}\text { Cokelat } \\
\text { muda }\end{array}$ & $\begin{array}{l}\text { Cokelat } \\
\text { muda }\end{array}$ & $\begin{array}{l}\text { Cokelat } \\
\text { muda }\end{array}$ \\
\hline & $\mathrm{B}$ & $\begin{array}{l}\text { Cokelat } \\
\text { muda }\end{array}$ & $\begin{array}{l}\text { Cokelat } \\
\text { muda }\end{array}$ & $\begin{array}{l}\text { Cokelat } \\
\text { muda }\end{array}$ & $\begin{array}{l}\text { Cokelat } \\
\text { muda }\end{array}$ \\
\hline & $\mathrm{C}$ & Cokelat tua & Cokelat tua & Cokelat tua & Cokelat tua \\
\hline \multirow[t]{3}{*}{ Bau } & A & $\begin{array}{c}\text { Khas green } \\
\text { tea }\end{array}$ & $\begin{array}{c}\text { Khas green } \\
\text { tea }\end{array}$ & $\begin{array}{c}\text { Khas green } \\
\text { tea }\end{array}$ & $\begin{array}{c}\text { Khas green } \\
\text { tea }\end{array}$ \\
\hline & $\mathrm{B}$ & $\begin{array}{c}\text { Khas green } \\
\text { tea }\end{array}$ & $\begin{array}{c}\text { Khas green } \\
\text { tea }\end{array}$ & $\begin{array}{c}\text { Khas green } \\
\text { tea }\end{array}$ & $\begin{array}{c}\text { Khas green } \\
\text { tea }\end{array}$ \\
\hline & $\mathrm{C}$ & $\begin{array}{c}\text { Khas green } \\
\text { tea }\end{array}$ & $\begin{array}{c}\text { Khas green } \\
\text { tea }\end{array}$ & $\begin{array}{c}\text { Khas green } \\
\text { tea }\end{array}$ & $\begin{array}{c}\text { Khas green } \\
\text { tea }\end{array}$ \\
\hline \multirow[t]{3}{*}{ Bentuk } & A & Semi padat & semi padat & semi padat & semi padat \\
\hline & B & semi padat & semi padat & semi padat & semi padat \\
\hline & $\mathrm{C}$ & semi padat & semi padat & semi padat & semi padat \\
\hline
\end{tabular}


Keterangan:

$\mathrm{A}=$ Hand and Body lotion dengan konsentrasi ekstrak daun muda jambu mete $2 \%$

$\mathrm{B}=$ Hand and Body lotion dengan konsentrasi ekstrak daun muda jambu mete $3 \%$

$\mathrm{C}=$ Hand and Body lotion dengan konsentrasi ekstrak daun muda jambu mete $5 \%$

Uji organoleptik dilakukan dengan cara mengamati secara visual terhadap bentuk, warna, dan bau sediaan. Berdasarkan Tabel 1. hasil pengujian pada ketiga formula hand and body lotion selama 4 minggu penyimpanan pada suhu kamar yaitu hasil pengamatan bentuk, diketahui bahwa seluruh sediaan hand and body lotion yang dibuat memiliki bentuk dan konsistensi yang baik. Hal tersebut terbukti dengan tidak terpisahnya fase minyak serta fase air.

\section{b. Pengujian Homogenitas}

Tabel 2. Hasil uji homogenitas Hand and body lotion ekstrak daun muda Jambu Mete

\begin{tabular}{ccccc}
\hline \multirow{2}{*}{ Formula } & \multicolumn{4}{c}{ Minggu } \\
\cline { 2 - 5 } & I & II & III & IV \\
\hline A & Homogen & Homogen & Homogen & Homogen \\
\hline B & Homogen & Homogen & Homogen & Homogen \\
\hline $\mathbf{C}$ & Tidak homogen & Tidak homogen & Tidak homogen & Tidak homogen \\
\hline
\end{tabular}

Parameter yang diamati dalam uji kestabilan fisik ini meliputi perubahan warna, bau, dan bentuk. Aroma yang dihasilkan dari seluruh sediaan adalah bau khas dari pengaroma yang digunakan yaitu pengaroma green sedangkan warna yang terlihat dalam pengamatan selama empat minggu yaitu warna coklat muda dan coklat tua, bentuk sediaan semi padat, aroma yang digunakan aroma green tea dan tidak mengalami perubahan selama penyimpanan. Stabilnya sediaan hand and body lotion dari ekstrak daun muda jambu mete dipengaruhi oleh kandungan antioksidan yang sangat tinggi pada daun muda jambu mete. 
Uji homogenitas merupakan pengujian yang bertujuan untuk mengetahui ada tidaknya butiranbutiran kasar pada sediaan serta tercampurnya bahan aktif dan bahan tambahan secara homogen, yang dilakukan dengan cara meletakkan sedikit lipstik cair di atas kaca objek. Untuk hasil pengujian homogenitas berdasarkan Tabel 2. Pengujian homogenitas diperoleh hasil dari formula A dan formula B tidak terdapat butiran-butiran kasar ketika dioleskan di atas objek glass, dan pada formula C terdapat butiranbutiran kasar diatas ketika dioleskan di atas objek glass. Sehingga dapat dikatakan bahwa formula A dan B yang diuji homogen.

\section{c. Pengujian pH}

Tabel 3. Hasil uji pH Hand and body lotion ekstrak daun muda Jambu Mete

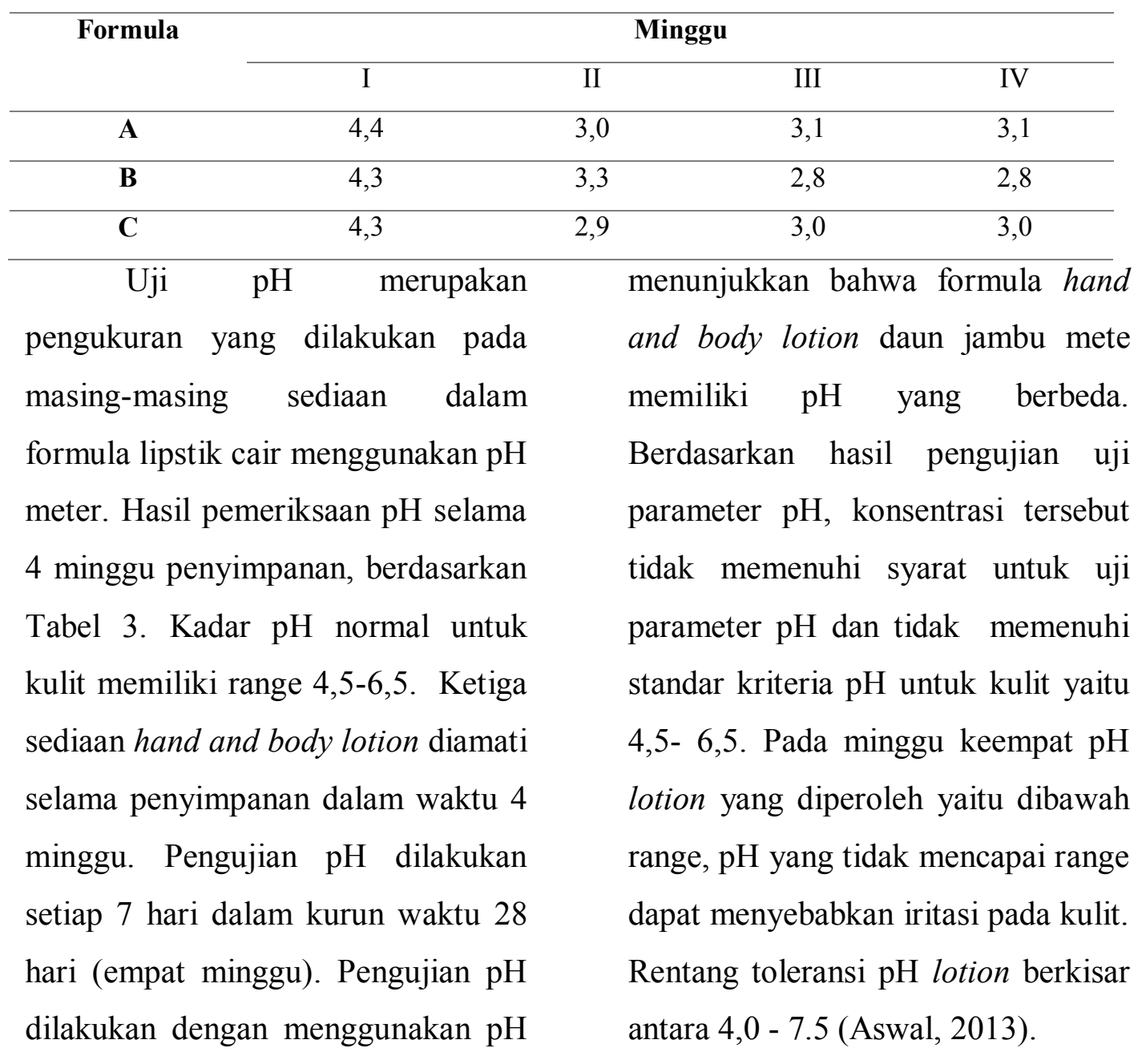
meter. Hasil pengujian $\mathrm{pH}$ 


\section{d. Pengujian Viskositas}

Tabel 4. Hasil uji viskositas Hand and body lotion Ekstrak daun muda Jambu Mete

\begin{tabular}{|c|c|}
\hline Formula & Uji Viskositas (dPa.s) \\
\hline I & IV \\
\hline 340 & 280 \\
\hline 350 & 300 \\
\hline 340 & 240 \\
\hline $\begin{array}{l}\text { Uji viskositas merupakan } \\
\text { pengujian yang dilakukan pada } \\
\text { masing-masing }\end{array}$ & $\begin{array}{l}\text { penambahan ekstrak pada tiap } \\
\text { formula sehingga mempengaruhi } \\
\text { viskositas sediaan (Zath, dkk, 1996). }\end{array}$ \\
\hline menggunakan viscometer yang & Hasil pengujian \\
\hline bertujuan untuk mengetahui & dilakukan dari ketiga formula lotion \\
\hline kekentalan dan aliran pada sediaan. & yaitu terjadi penurunan viskositas \\
\hline Hasil pengujian viskositas & pada minggu ketiga dan keempat. \\
\hline berdasarkan Tabel 4. dari ketiga & Hal ini menunjukkan bahwa semakin \\
\hline formula pada minggu pertama & besar konsentrasi ekstrak maka nilai \\
\hline hingga minggu keempat yaitu & viskositas sediaan \\
\hline terjadinya peningkatan viskositas & semakin tinggi atau sediaan akan \\
\hline dari formula $\mathrm{A}$ ke formula $\mathrm{C}$, adanya & semakin kental. \\
\hline perbedaan viskositas pada masing- & \\
\hline formula dikarenakan & \\
\hline
\end{tabular}




\section{e. Uji Tipe Emulsi}

Tabel 5. Uji Tipe Emulsi Hand and body lotion Daun Muda Jambu Mete

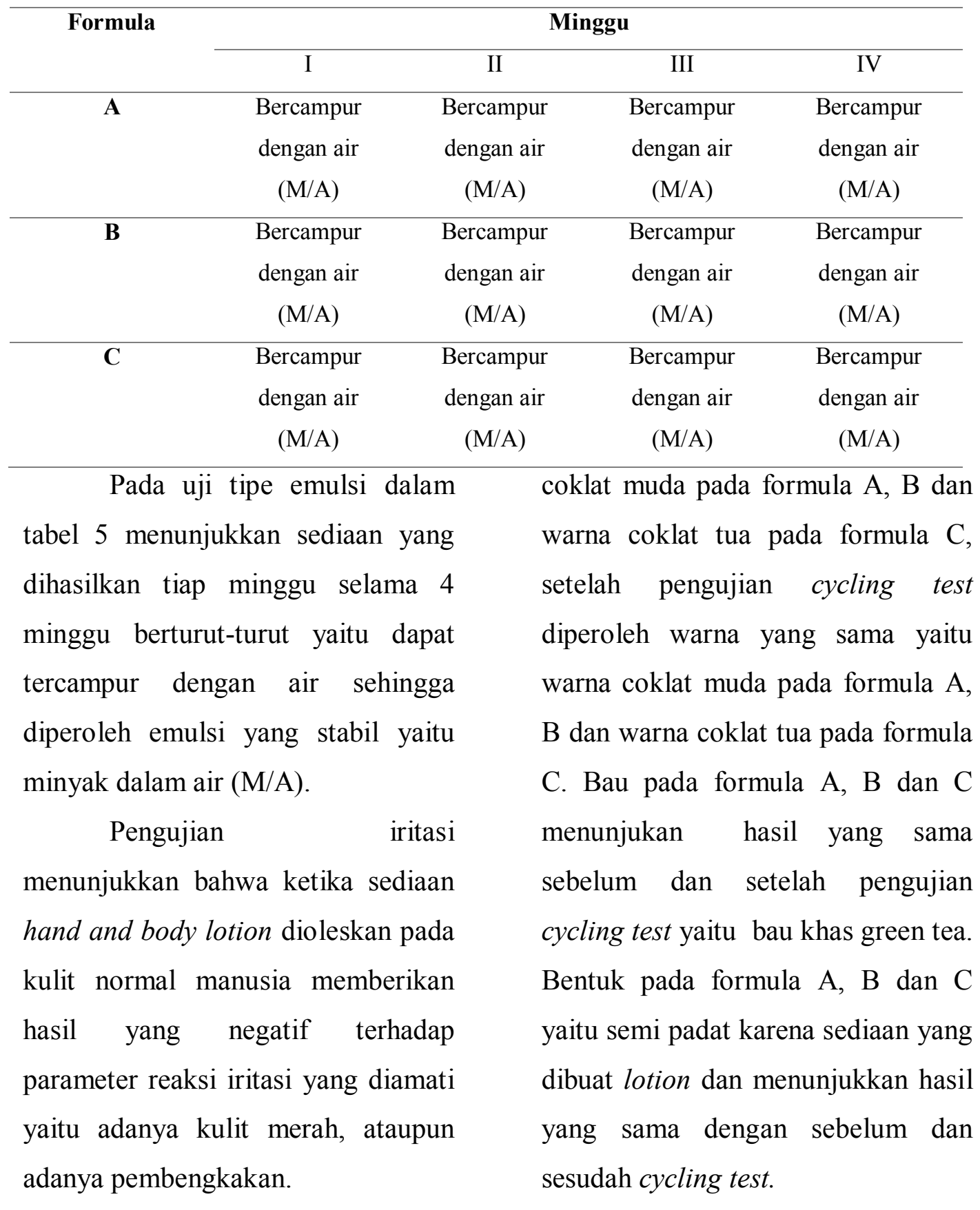

Uji cycling test dilakukan pengamatan organoleptik yang meliputi warna, bau dan bentuk. Sebelum pengujian cycling test warna sediaan menunjukkan warna

\section{KESIMPULAN}

Berdasarkan hasil penelitian yang dilakukan mengenai formulasi sediaan hand and body lotion dari ekstrak daun muda jambu mete, 
diperoleh kesimpulan yaitu Ekstrak daun muda jambu mete dapat diformulasi menjadi sediaan hand and body lotion namun sediaan yang diperoleh belum memenuhi syarat evaluasi fisik berdasarkan uji $\mathrm{pH}$.

\section{DAFTAR PUSTAKA}

Anief, moh.1997. Formulasi Obat

Topical Dengan Dasar

Penyakit Kulit. Gadja Mada

University : Yogyakarta

Aswal, A., Karla, M., \& Rout, A.

2013. Preparation and

Evaluation of Polyherbal

Cosmetic Cream. Der

Pharmacia Lettre.

Badan POM. 2004. Peraturan

Perundang-Undangan di

Bidang Kosmetik. Badan
Pengawas Obat dan Makanan

Republik Indonesia :Jakarata

Hakimah, L.A. 2012. 81 macam buah berkhasiat istimewa. Yogyakarta.

Winarsi,H.2007.Antioksidan Alami dan Radikal Bebas. Penerbit kanisius. Yogyakarta.

Wasitaatmadja. 1997. Penuntun Ilmu Kosmetik Medik. Universitas Indonesia : Jakarta

Zath, dkk. 1996. Pharmaceutical Dosage Form: Dysperse System Vol. 2. 2nd Ed, P.399417. New York: Marcell Dekker, Inc. 